are closely associated with the neighbourhood of the luminescence centres and can be formed by the introduction of the impurity giving rise to the centres. (b) Retrapping of electrons is usually a negligible process in the luminescence mechanism of zinc sulphide and other specific phosphors. This statement is capable of explanation in terms of that in $(a)$.

An earlier communication in Nature ${ }^{3}$, from Mr. Klasens alone, postulated a theoretical explanation of the energy exchange in sulphide phosphors with more than one impurity. Experimental facts arising from our studies do not support this simple theory. As an example, the figure given in this earlier communication showing the effect of nickel on a zinc sulphide-silver-activated phosphor agrees approximately with our results. However, the increase of nickel content not only affects the ratio of killer centres to emission centres, but also causes a large change in the $E$ value contained in the expression for the parameter $c$. The theory does not explain the fluorescence-excitation intensity relations found for very low excitation of these phosphors in the tem. perature region where the value of $c$ becomes important.

We believe that Mr. Klasens' views are not adequately supported by experimental evidence, which seems to favour different basic assumptions.

G. F. J. Garlick

A. F. GiBson

Physics Department,

University of Birmingham.

Oct. 5 .

${ }^{1}$ Klasens, H. A., and Wise, M. E., Nature, 158, 483 (1946).

${ }^{2}$ Randall, J. T., and Wilkins, M. H. F., Prøc. Roy. Soc., A, 184, 366 and $390(1945)$.

s Klasens, H. A., Nature, 158, 306 (1946).

\section{Diamagnetic Susceptibility of Isomerides}

IN a discussion of investigations on the magnetic susceptibilities of aliphatic acids and esters-carried out just before the outbreak of war and published ${ }^{1}$ in 1943-Angus and Hill directed attention to certain regular differences between the susceptibilities of straight-and branched-chain compounds and briefly rèviewed existing data.

When the study of magnetic susceptibilities was resumed by us about a year ago, investigation of various types of isomerides was planned and, in the first instance, more particularly aldehyde-ketone isomerism and the isomers of methyl benzoate and their analogues, sinee, from the few relevant published data $^{2}$, it appeared that such isomerides had identical susceptibilities. While these investigations were proceeding, there appeared in the issue for March 12 of the Comptes rendus ${ }^{3}$ a paper by Pascal and Pacault; unfortunately, it was only a few days ago that this paper became available to us. Pascal and Pacault discuss, in a generally adverse manner, the results on isomers of aliphatic acids and esters ${ }^{1}$, and suggest the desirability for carrying out further investigation on isomerides which appeared to have identical susceptibilities. This work was, as has been stated, in hand and has now reached a sufficiently advanced stage to make a preliminary report appear to be desirable, although reserving a discussion of the significance of susceptibility differences until the planned programme has been completed and the values now given have been adequately confirmed. It is not proposed to refute here the general criticisms contained in Pascal and Pacault's paper ; that can and will be done elsewhere later.

So far our work on aldehyde-ketone isomerides has shown that the aldehyde is slightly more diamagnetic than the isomeric ketone, although, with our present data, the difference shows a small but not a constant value. For example, the value for acetone is $0.4 \times 10^{-8}$ less diamagnetic than propionaldehyde, while with methyl amyl ketone and œnanthaldehyde the difference is $0.7 \times 10^{-6}$.

The results for the other type of isomerism which we have studied are more self-consistent and give more regular differences, as is shown in the accompanying table showing the values of $-\chi_{M}$ (multiplied by $10^{6}$ ) obtained.

\begin{tabular}{|c|c|c|c|c|c|}
\hline $\begin{array}{l}\text { Phenyl- } \\
\text { acetates }\end{array}$ & \multirow{2}{*}{$\begin{array}{c}\text { Benzyl esters } \\
\text { Formate } 81.43 \\
\text { Acetate } 93.18\end{array}$} & \multicolumn{2}{|c|}{ Benzoates } & \multicolumn{2}{|c|}{ Phenyl esters } \\
\hline $\begin{array}{lr}\text { Me } & 92 \cdot 73 \\
\text { Et } & 104 \cdot 27\end{array}$ & & $\begin{array}{l}\text { Me } \\
\text { Et } \\
\text { Pr }\end{array}$ & $\begin{array}{r}81 \cdot 54 \\
93 \cdot 32 \\
105 \cdot 00\end{array}$ & $\begin{array}{l}\text { Acetate } \\
\text { Propionate } \\
n \text {-Butyrate }\end{array}$ & $\begin{array}{r}82 \cdot 04 \\
93 \cdot 79 \\
105 \cdot 46\end{array}$ \\
\hline
\end{tabular}

These results show clearly that the isomerides do not have identical susceptibilities.

\section{W. Rogin Angus Geoffrey StotT}

Department of Chemistry, University College of North Wales,

Bangor.

Oct. 7.

1 Trans. Faraday Soc., 39, 185 (1943)

${ }^{2}$ Pascal, Ann. Chimie, 19; 5 (1910).

${ }^{3}$ C.R. Acad. Sci. Paris, 222, 619 (1946).

\section{X-Ray Examination of Self-Recovery in Copper}

A communicatron by L. L. Van Reijen ${ }^{1}$ refers to a recovery effect after an interval of some months in filed copper powder. This was shown by X-ray transmission photographs of a thin layer of the powder specimen. He used the same interval of time when verifying his observation, and presumably did not follow the progress of recovery in detail. However, in view of his reference to rotation powder photographs taken by Megaw, Lipson and Stokes $\mathbf{s}^{2,3}$, in which recovery was detected some days after the preparation of the powder, it may be of interest to report that we have detected the self-recovery of filings of electrolytic tough pitch copper several days after filing, in both transmission photographs and rotation powder photographs.

The transmission method is preferable for following the progress of recovery during its later stages; thus the diffraction pattern obtained with the freshly filed copper shows diffuse diffraction rings of uniform intensity, and after six days a number of intense sharply defined spots appear superimposed on a background of the diffuse reflexions. After an interval of eleven days the intensity and size of the individual reflexion spots increase, and after twenty-four days the diffraction rings are beginning to become discontinuous and tend to break up into individual spots.

The presence of very small amounts of impurities is known to exert an appreciable influence on the atomic rearrangement necessary for self-recovery and recrystallization to occur. Some years ago, other investigators ${ }^{4,5}$ used X-rays to study the time of recrystallization at room temperature of two different samples of electrolytic copper in the form of cold- 